\title{
Marching beyond the sella: Gerard Guiot and his contributions to neurosurgery
}

\author{
Khaled M. Krisht, MD, ${ }^{1}$ Mohammad Sorour, MBBS, ${ }^{1}$ Martin Cote, MD, ${ }^{1}$ Jules Hardy, MD, ${ }^{2}$ \\ and William T. Couldwell, MD, PhD'
}

'Department of Neurosurgery, Clinical Neurosciences Center, University of Utah, Salt Lake City, Utah; and 2Department of
Neurosurgery, Centre Hospitalier de l'Université de Montréal, Quebec, Canada

Gerard Guiot (1912-1998) was one of the most renowned and innovative neurosurgeons of the 20th century. His pivotal and revolutionary role in advancing transsphenoidal surgery has been recorded in many historical vignettes, yet his outstanding contributions to the advancement of neurosurgery outside the confines of the sella have not been described in a detailed fashion. In this article, the authors discuss the life and achievements of Professor Guiot and present a comprehensive description of his contributions to the field of neurosurgery, including cerebrovascular, spine, craniofacial, stereotactic functional, and endoscopic surgery.

http://thejns.org/doi/abs/10.3171/2014.10.JNS131919

KEY WORDS transsphenoidal; ventriculocisternostomy; hypertelorism; cardiac standstill; kyphoscoliosis; fluoroscopy; endoscopy; history

$\mathrm{G}$ ERARD Guiot's name is mentioned in many articles that discuss the historical evolution of transsphenoidal pituitary surgery, and his work and contributions to that technique are praised alongside those of his mentor Norman Dott and his "spiritual grandfather" Harvey Cushing. Guiot is lauded for preserving the transsphenoidal approach and elevating it to new heights through the introduction of live intraoperative fluoroscopy. While we duly honor his instrumental role in advancing pituitary surgery, we forget to celebrate his other remarkable contributions to the field of neurosurgery, which remain unknown to many in the neurosurgical community. Among his numerous achievements in the fields of neurosurgery and neurology are the discovery of the corneopterygoid reflex, the introduction of the subtemporal approach for mesencephalic tractotomy to treat pain and peduncular tractotomy for parkinsonian tremors, the popularization of the parasagittal approach to the basal ganglia, and the introduction of innovative stereotactic functional techniques. He played a fundamental role in the study and understand- ing of subcortical electrophysiology and implemented the technique in the treatment of functional disorders, as demonstrated by his microelectrode recordings of cell units and stimulation of the internal capsule, which helped to delineate various thalamic nuclei to within a $0.5-\mathrm{mm}$ accuracy. In this article, we present a comprehensive account of Guiot's life and discuss his invaluable contributions to diverse subdisciplines in neurosurgery including neuroendoscopy, craniofacial surgery, functional neurosurgery, cerebrovascular surgery, spine deformity surgery, and transsphenoidal surgery.

\section{Gerard Guiot: the Man, the Surgeon, the Gardener Musician}

Gerard Guiot was born to a Catholic family in January 1912 in the small northern border town of Fourmies, France, known for its annual hosting of the professional cycle race Grand Prix de Fourmies (Fig. 1). Growing up, he had a strong musical inclination, and his love of mu- 


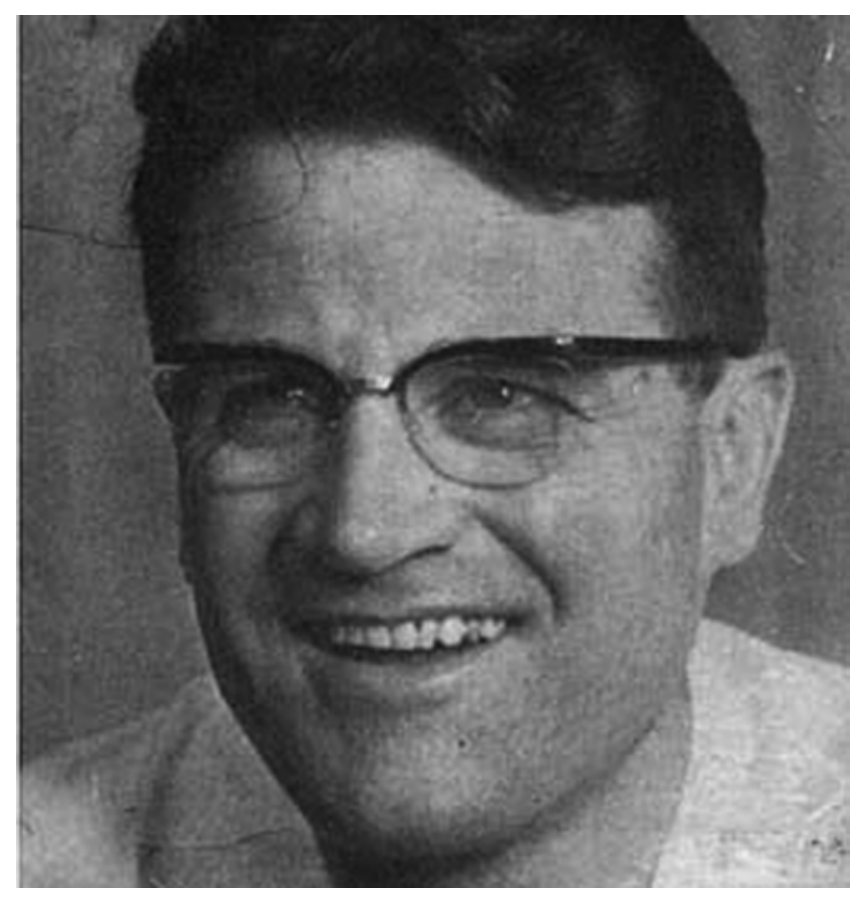

FIG. 1. Gerard Guiot (1912-1998), age 50 years, a pioneer in transsphenoidal surgery. Reproduced from Grosvenor AE, Laws ER: Pituitary 11:337-345, 2008. With kind permission from Springer Science and Business Media.

sic would manifest itself throughout his life until his final days, yet this early talent was supplanted by his accomplishments in medicine. ${ }^{23}$ Guiot attended the Medical School of Paris and graduated with a laureate distinction and the Silver Medal in 1937 (Fig. 2). On March 6 of that year, at the age of 25 years, he married Elise Bouettery, who bore him 4 daughters. Guiot trained in neurosurgery under the tutelage of Professor R. Garcin in Paris. Professor D. Petit-Dutaillis at l'Hôpital de la Pitié-Salpêtrière in Paris was also influential to Guiot and one of his early mentors. After Guiot's training in Paris, he met Professor Clovis Vincent, who was a neurologist by training but developed neurosurgical skills by observing Harvey Cushing. Vincent imported to France the techniques and concepts of Cushing, and Guiot adopted these techniques after he became Vincent's pupil. ${ }^{38}$

Professor Norman Dott of Edinburgh,,$^{12}$ one of the giants of neurosurgery at the time and a visionary neurosurgeon, proved to have the greatest influence on Guiot. From Dott, Guiot would learn the transsphenoidal approach to pituitary tumors and would go on to improve and perfect his techniques, thus revitalizing the use of the transsphenoidal approach in France. . $^{6,12,34,38}$ In 1956, Guiot founded the Department of Neurosurgery at l'Hôpital Foch (Suresnes-Paris), where he introduced the first "fulltime" system to France, where all faculty members were on a salary without running private neurosurgical practices. During his tenure at l'Hôpital Foch, Guiot introduced many of his new techniques. ${ }^{38} \mathrm{He}$ was the first neurosurgeon to perform a neurosurgical procedure under complete cardiac and circulatory arrest in 1960. In 1962, he developed a new ventriculoscope, which he used for ventriculocisternostomies with television control for the treatment of hydrocephalus from aqueductal stenosis. ${ }^{16}$

Guiot published more than 300 scientific publications and inspired over 30 doctoral theses. He was awarded the class of Officier in the Ordre National du Mérite, the national merit award of France, by President Charles De Gaulle in 1966. In 1968, he was elected as an honorary member of the Society of Neurological Surgeons, the oldest neurosurgical society in the world. Founded in 1920 as a travel club, the Society's twice-yearly meetings aimed to allow neurosurgeons from around the world to learn from each other through case presentations and demonstrations of various interesting surgical procedures (http://www.so cietyns.org/history/index.html). Guiot's membership put France on the map of places with modern and innovative neurosurgery and helped to attract many American and Canadian neurosurgeons to France. Among these was his student Jules Hardy, whose introduction of the microscope to transsphenoidal surgery led to a new era of microsurgical innovation.

Guiot was named Neurosurgeon of the Year in 1979. ${ }^{23}$ At his prime, he was performing 400 major operations a year; at this time, his series included more than 1500 pituitary adenomas. In 1976, a decade before his final retirement, he still performed close to 200 cases per year.

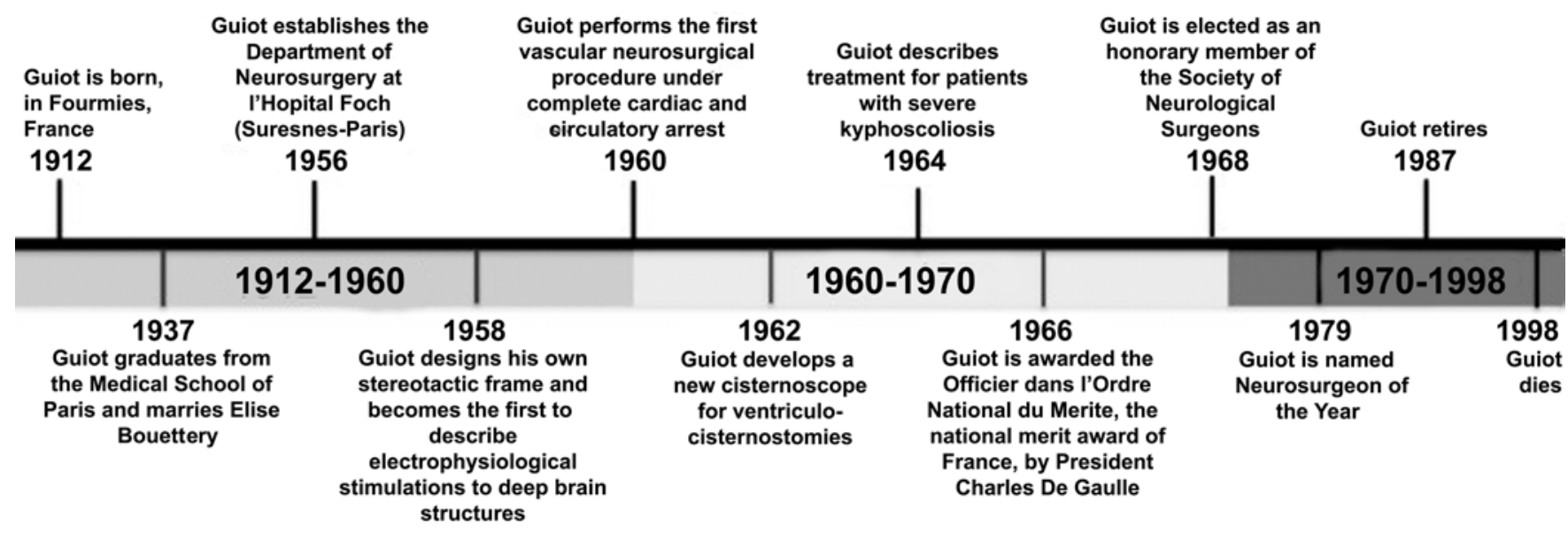

FIG. 2. Timeline illustrating important events in Guiot's life and career. 
Following his official retirement on January 1, 1987, Guiot took up gardening in the old farm village of Les Molières, a commune in the Essonne department of northern France. His final years were focused on gardening, participating in biblical studies, and enjoying music. ${ }^{23}$

\section{Guiot's Contributions to Neuroendoscopy}

Neuroendoscopy was pioneered in the early 1910s by Lespinasse, a urologist from Chicago, who introduced a small cystoscope into the ventricular system for the treatment of noncommunicating hydrocephalus through obliteration of the choroid plexus. This limited early use was followed by the emergence of the third ventriculostomy in $1923 . .^{10,51}$ Before the early 1960s, the light source in endoscopes was directly attached to the tip, which provided poor visualization of the ventricular system and discouraged the exploitation of neuroendoscopy for these uses. ${ }^{10}$ A compilation of videos demonstrates intraventricular endoscopy and removal of a pituitary adenoma undertaken by Guiot in 1962 (W.T. Couldwell, personal communication, 2012). In 1963, with innovations from the Institute of Optics in Paris, Guiot published his experience using the first endoscope with an external light source (cold light generator) that allowed for the transmission of light at variable intensities through a silica stem. This allowed for better visualization of the ventricular system, rendering endoscopic procedures safer, and made intraoperative photographing and video recording possible. ${ }^{16}$ Guiot was deemed a pioneer in reviving modern neuroendoscopy, although he later abandoned this procedure for an easier fluoroscopically guided technique for third ventriculocisternostomy. In this newer technique, a paramedian bur hole was made, through which a leukotome introduced into the lateral ventricle and the third ventricle pierced the floor of the third ventricle through a leukotome loop (Fig. 3). ${ }^{16}$

\section{Introducing Facial Reconstructive Surgery to the Neurosurgeon}

Guiot was a facile surgeon, thinker, and innovator. His interest in neurosurgery had no boundaries. He sought improvement and innovation in all facets of neurological surgery. While he thought of ways to navigate through and illuminate the intraventricular space, he was equally interested in exocranial pathology as highlighted by his contributions to maxillofacial surgery. This surgical specialty had a strong emergence during World War I, as multiple challenging facial injuries were encountered throughout the war. During this time, plastic reconstructive surgery was blossoming as a separate specialty, but not until the early 1960s were facial surgeries performed by a multidisciplinary maxillofacial team consisting of plastic reconstructive surgeons; ear, nose, and throat surgeons; and anesthesiologists. Facial reconstructive surgery at that time, however, was performed via a purely extracranial approach ${ }^{44}$ In 1963, Paul Tessier, a plastic surgeon working at the same hospital as Guiot, introduced his neurosurgeon colleague to the multidisciplinary team, which he thereafter named "the craniomaxillofacial team." ${ }^{23,44}$ That same year, as he was planning a very complicated operation

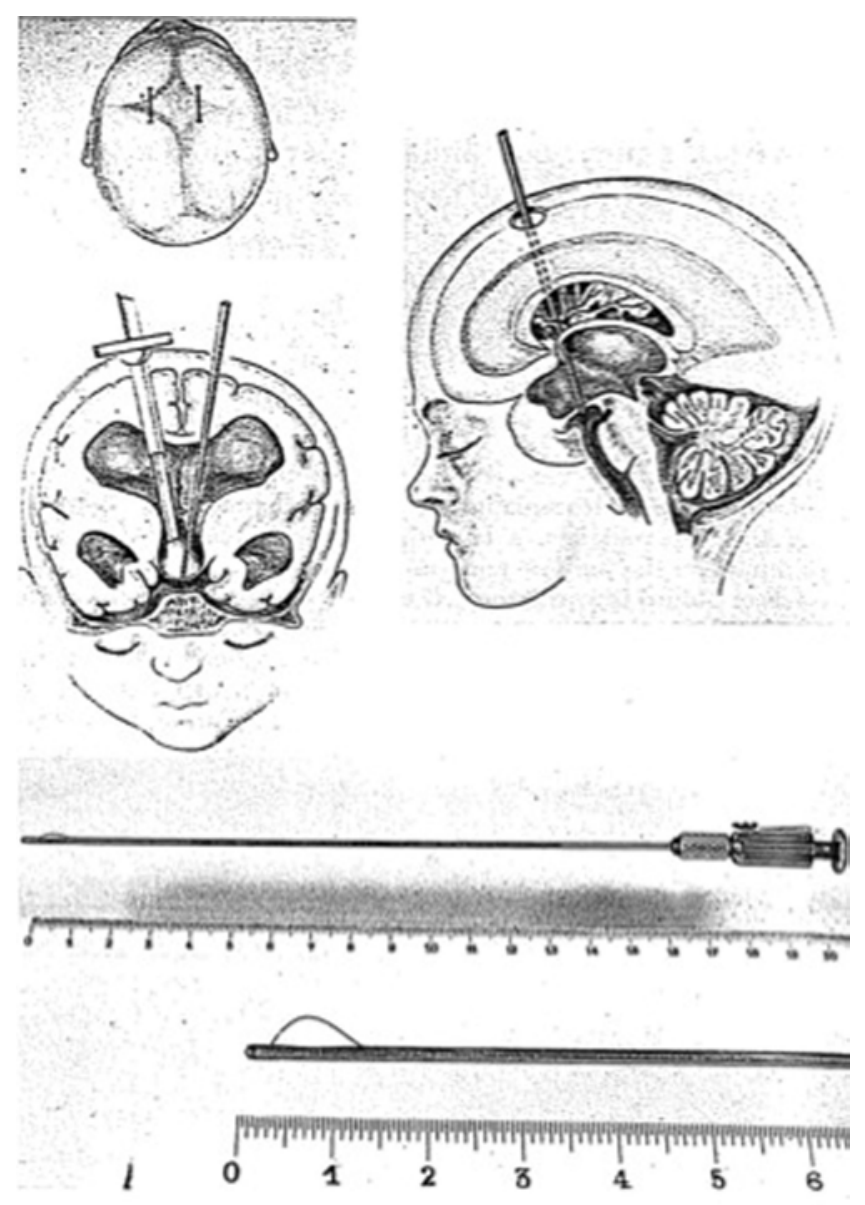

FIG. 3. Ventriculocisternostomy under ventriculoscopic control. Upper Left: Endoscopic illumination of the third ventricular floor through the foramen of Monro. Upper Right: Introduction of the perforating spatula under visual control. Lower: Leukotome, smaller and magnified views, used for ventriculocisternostomy under television control. Reproduced with kind permission from Springer Science+Business Media: Acta Neurochir (Wien), Ventriculo-cisternostomy for stenosis of the aqueduct of Sylvius. Puncture of the floor of the third ventricle with a leucotome under television control, Vol 28, 1973, pp 275-289, Guiot G.

for hypertelorism in a patient with Crouzon's syndrome, Tessier asked his neurosurgeon colleague about the possibility of opening the anterior fossa to expose the orbits and the ethmoid region. After some hesitation and deliberation Guiot's answer was, "Pourquoi pas?" (why not?). ${ }^{44}$ The surgery was a success, and in 1973 they proceeded to publish their experience on the surgical management of hypertelorism in Crouzon's syndrome via the craniofacial route (Fig. 4) ${ }^{47}$ During the intracranial portion of the surgery, Guiot performed several orbital osteotomies along with subtotal drilling of the ethmoid bone, preserving the cribriform plate to maximize the chances of preserving olfaction and preventing CSF leakage. The new technique for the management of hypertelorism was described at that time as being more successful than earlier purely extracranial techniques, as it allowed for radical correction of this condition by improving approximation of the orbits to each other while ensuring preservation of the cribriform plate and avoiding dural tears and subsequent CSF leak- 


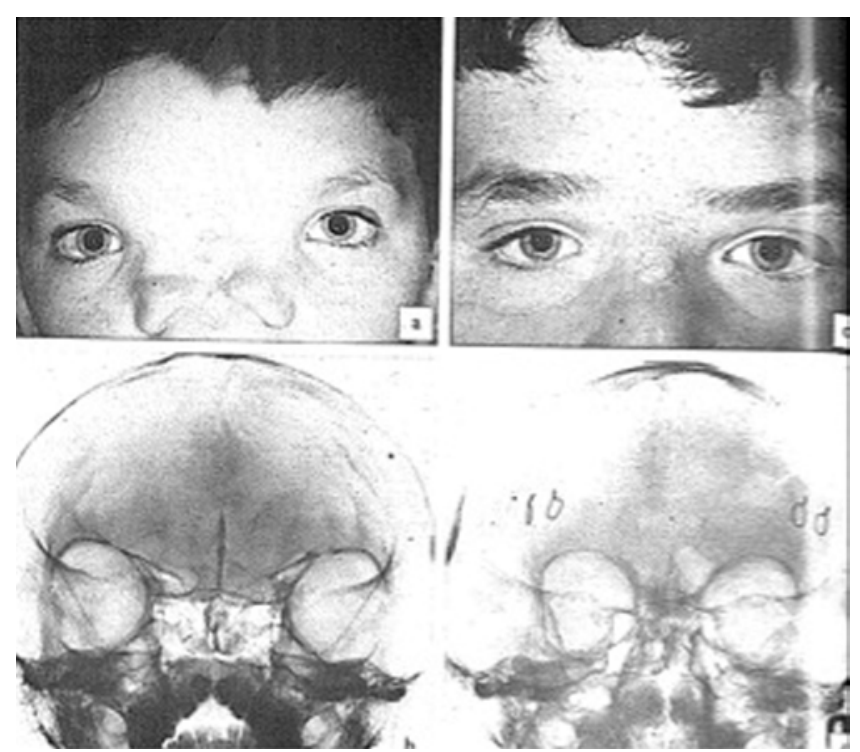

FIG. 4. Medial dysgraphia, bifid nose, medial cleft of the upper lip before (upper left) and after (upper right) a three-step procedure involving craniofacial osteotomy, ethmoidectomy, and Z plasty of the frontonasal angle. The respective radiographs (lower left and right) appear directly underneath the photos. Tessier P, Guiot G, Derome P: Scand J Plast Reconstr Surg 7:39-58, copyright @ 1973, Informa Healthcare. Reproduced with permission.

age. ${ }^{47}$ This innovation facilitated the development of complete reconstruction of orbitofacial dysostosis and the en bloc excision of the meningiomas of the sphenoid wing. ${ }^{23}$

\section{The Guiot-Gillingham Stereotactic Frame and Guiot's Impact on Functional Neurosurgery}

Guiot's contributions to functional neurosurgery began early in his neurosurgical career. In 1947, Guiot described the subtemporal approach to the brainstem, which he later applied in treating chronic pain and parkinsonian tremors via mesencephalic tractotomy and peduncular tractotomy, respectively. ${ }^{23}$

In Paris in 1958, Guiot designed a stereotactic frame that was subsequently modified and applied by Gillingham in Edinburgh. ${ }^{14}$ This frame advanced earlier models and increased the target accuracy. After Victor Horsley and Robert Henry Clarke ${ }^{29}$ designed the first animal stereotactic apparatus in 1908, 40 years passed before Spiegel and Wycis ${ }^{45}$ introduced a modified apparatus for use in humans.$^{40}$ Over the next few years, several neurosurgeons designed their own stereotactic frames, including Leksell, Narabayashi, Talairach, and others. ${ }^{35,40,46,48}$ The Guiot-Gillingham stereotactic frame was among the most accurate and safest means to address the target areas to be treated in Parkinson disease and offered simplicity and a relatively short intraoperative period for apparatus placement (Fig. 5). ${ }^{41}$

Guiot then began a series of technical innovations in the field of functional neurosurgery that used his frame to enable targeting of several deep brain structures in treating movement disorders. ${ }^{5,32}$ The concept of using thermal coagulation in various deep brain areas was described in

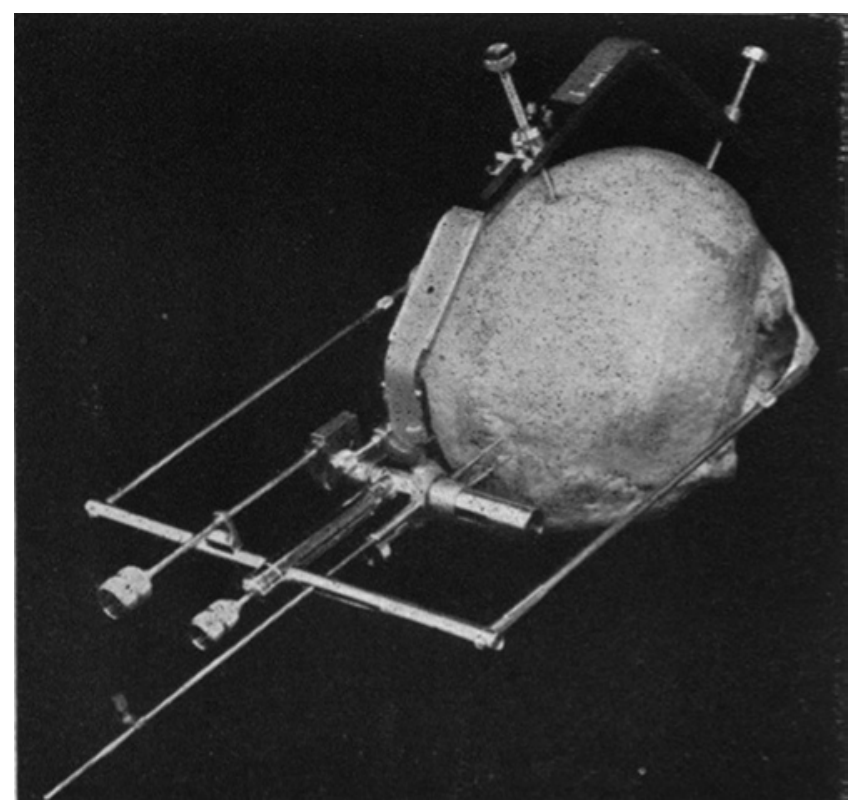

FIG. 5. Guiot-Gillingham stereotactic frame. Reproduced from $\mathrm{Br}$ Med J, Gillingham F, Watson W, Donaldson A, Naughton J, Vol 12, pp 13951402, 1960, with permission from BMJ Publishing Group Ltd.

1949 by Talairach and colleagues ${ }^{11}$ and Hecaen and associates, ${ }^{37}$ who targeted the thalamus in treating intractable pain. Later, in 1954, Hassler et al..$^{28}$ used the same concept in treating dyskinesia. In 1958, however, Guiot was the first to describe electrophysiological stimulation of deep brain structures prior to thermal coagulation. ${ }^{19,40}$ This was a precursor to the modern stimulation technique involving implanted electrodes. The use of the frame allowed Guiot to aim for better mapping of the thalamic nuclei, internal capsule, and globus pallidus and consequently allowed for more precise targeting of the ventral lateral nucleus of the thalamus, which was his target in treating parkinsonian tremors, rendering the procedure safer and more successful (Fig. 6). In 1961, Guiot and Madame D. Albe-Fessard described a group of subcortical neurons they called "tremor cells," which fired in bursts at frequencies similar to those of the tremors, shedding light on the pathophysiology of tremor-related disorders, such as Parkinson disease and essential tremor, and helping to explain possible differences in the efficacy of a specific target between the different basal ganglia tremor disorders. ${ }^{2,36}$

The Hôpital Foch, where Guiot practiced his neurosurgical innovations, was described as one of the two leading French stereotactic units of its time. This made it an inspiring teaching center to neurosurgeons in both Europe and North America, facilitating the exchange of ideas and knowledge across continents. Lauri Laitinen, a Finnish functional neurosurgeon and one of the world-renowned second-generation pioneers in stereotactic neurosurgery, described his visit to Paris in 1963 when Professor Guiot and Madame D. Albe-Fessard introduced him to microelectrode recording for the first time. In his personal memories, Laitinen wrote, "In fact, I found that the few weeks in Paris were more important for my future than the months I spent in Freiburg." 33 


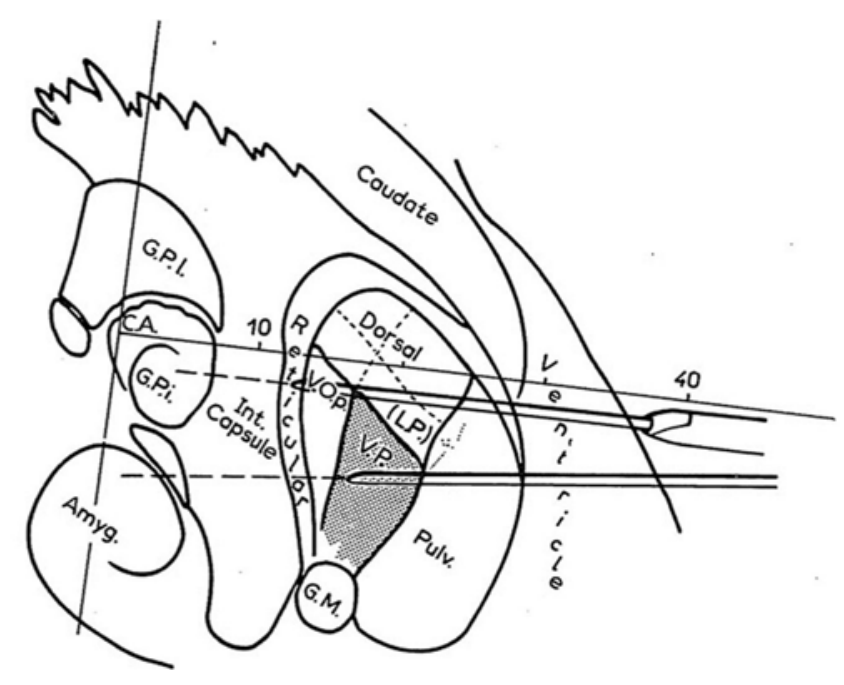

FIG. 6. Sagittal section through the thalamus showing two of Guiot's preferred trajectories to the ventrolateral thalamus for the treatment of Parkinson disease. Amyg. = amygdala; C.A. = cornu ammonis; G.M. = medial geniculate; G.P.i. = globus pallidus externus; G.P.I. = globus pallidus internus; Int. = internal; L.P. = lateral posterior nucleus; Pulv. = pulvina; V.O.p. = ventralis oralis posterior; V.P. = ventral posterior nucleus. Reprinted from J Neurol Sci, Vol 3, Albe-Fessard D, Arfel G, Guiot G, Derome P, Hertzog E, Vourc'h G, et al., Electrophysiological studies of some deep cerebral structures in man, pp 37-51, Copyright 1966, with permission from Elsevier.

Guiot's contributions to the field of functional neurosurgery were not exclusive to operating in humans. $\mathrm{He}$ published several animal studies aimed at improving understanding of the pathophysiology behind Parkinson disease and other movement disorders. For example, he performed hemicerebellectomies in 15 baboons, after which he tried to perform electrostimulation of the ventrolateral thalamic nuclei and concluded that the cerebellum has a role in lowering seizure activity by inhibitory mechanisms on the thalamocortical pathways. ${ }^{49}$

\section{Guiot's Application of Hypothermic Cardiac Standstill to Treat Cerebrovascular Malformations}

Guiot had a strong understanding of and a deep appreciation for the need for brain protection when tackling difficult vascular cases that posed the threat of vessel injury and subsequent tissue ischemia. Hypothermia-induced reduction in the cerebral metabolic rate had been introduced to provide neuronal protection for the resection of large intraaxial lesions, and Guiot was not afraid to expand its indications and implement the procedure in dealing with vascular pathology. In 1960, Guiot reported on the first arteriovenous malformation surgically treated with the patient under deep hypothermia at $10^{\circ} \mathrm{C}$ with complete circulatory arrest, making Guiot one of the first neurosurgeons to use this technique for difficult vascular lesions. ${ }^{21}$ The procedure was performed on January 26, 1960, only 1 year after the technique was first used by Woodhall and colleagues in a patient with a large left parietal metastatic lesion. ${ }^{50}$ Guiot's patient was an 18-year-old man with sei- zures and right paresis caused by a large left frontoparietal arteriovenous malformation (Fig. 7). After simultaneous craniotomy and sternotomy, the core temperature of the patient was lowered to $10^{\circ} \mathrm{C}$, and extracorporeal circulation was established. Resection of the malformation was completed in 43 minutes; thereafter, the patient was progressively warmed. Although the patient suffered from postoperative right plegia attributed to extension of the lesion into the internal capsule, he had no neuropsychological deficit after surgery despite a total ischemic time of 80 minutes. Encouraged by the hypothermic brain's tolerance to prolonged ischemia, Guiot used deep hypothermia and circulatory arrest again in 1964 in a case of a carotid cavernous aneurysm causing cavernous sinus syndrome. ${ }^{20}$ These early successes aroused considerable interest in the neurosurgical community and paved the way for other surgeons to approach cerebrovascular lesions that were otherwise considered inoperable.

\section{Guiot's Influence on Spinal Deformity Surgery}

Although Guiot was more involved with cranial neurosurgery, he enjoyed partaking in complex spine deformity surgery, which was well suited to his inquisitive and critical-thinking mind. In 1964, he described his technique for treating patients with severe kyphoscoliosis who suffered from paraplegia. ${ }^{17}$ In detailing how to optimally treat patients with spinal deformity and improve their overall clinical outcomes, he emphasized the need for open collaboration between orthopedic surgeons and neurosurgeons to find effective therapeutic strategies, as well as the importance of ensuring adequate spinal cord decompression, while underscoring the inefficacy of simple laminectomy.

Guiot's surgical technique consisted of resecting the
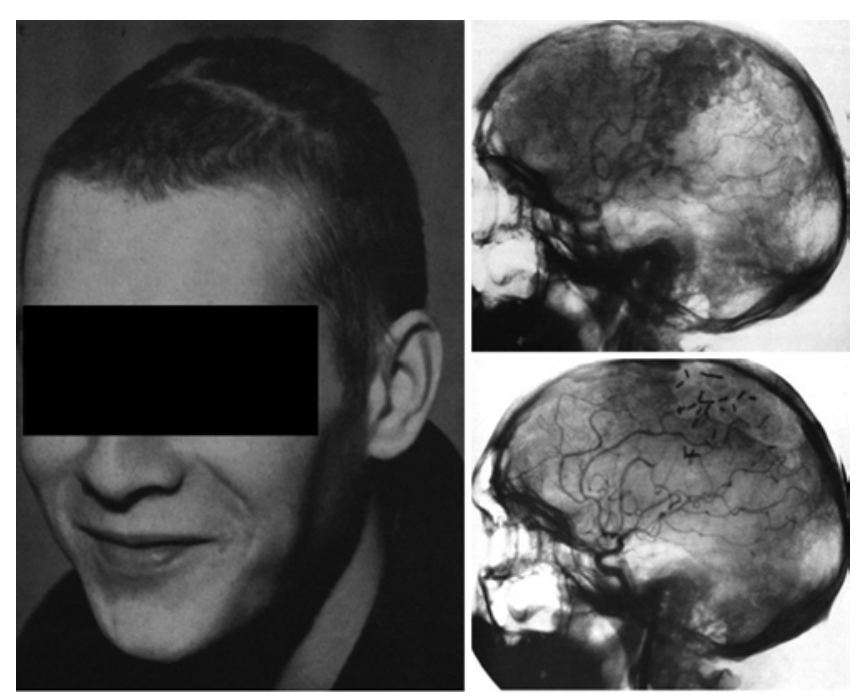

FIG. 7. First patient (left) to undergo complete surgical treatment of an arteriovenous malformation under hypothermic cardiac standstill, which was performed by Gerard Guiot in 1960. Radio-angiographic images before (upper right) and after (lower right) clip ligation of a left frontoparietal arteriovenous malformation. Reproduced from Guiot G, Rougerie J, Arfel G, Dubost C, Blondeau P: Neurochirurgie 6:332-346, 1960. 
laminae, pedicles, costotransverse joints, and posterolateral aspects of the vertebral bodies on the concave side of the curvature (Fig. 8). Performing this bony resection on 3-6 spinal levels allowed for decompression of the thecal sac and placed the spine in straighter alignment. Guiot then opened the dura mater laterally to allow for further translation of the spinal cord, leaving the arachnoid intact to prevent any spinal fluid leakage. Postoperative orthopedic treatment with casts or spinal fusion as well as physical therapy was an integral portion of the care for these patients. In Guiot's series of 9 patients, 6 had a complete neurological recovery, 2 who had suffered from traumatic paraplegia after a motor vehicle accident did not improve, and 1 patient who had made initial progress regressed after 6 months. ${ }^{17}$

\section{Guiot's Introduction of Live Intraoperative Image Guidance to Transsphenoidal Surgery}

Guiot's greatest contribution to modern-day neurosurgery was his impact on transsphenoidal surgery. Prior to his introduction of intraoperative image intensification, potentially hazardous migration beyond tumor boundaries sometimes occurred because the surgeon could not see clearly through the deep and dark working tunnel. This rightfully led more timid surgeons to leave behind a large number of subtotally resected lesions. To overcome this deficiency, soon after his first transnasal resection, Guiot introduced intraoperative image intensification and fluoroscopy to his armamentarium. These techniques allowed the surgeon for the first time to visualize and appreciate the depth and position of the surgical instruments during the procedure and to visualize tumor descent through the sellar floor. ${ }^{13,22,24}$ Guiot arranged the fluoroscopic setup in the operating theater, placing the television screen behind

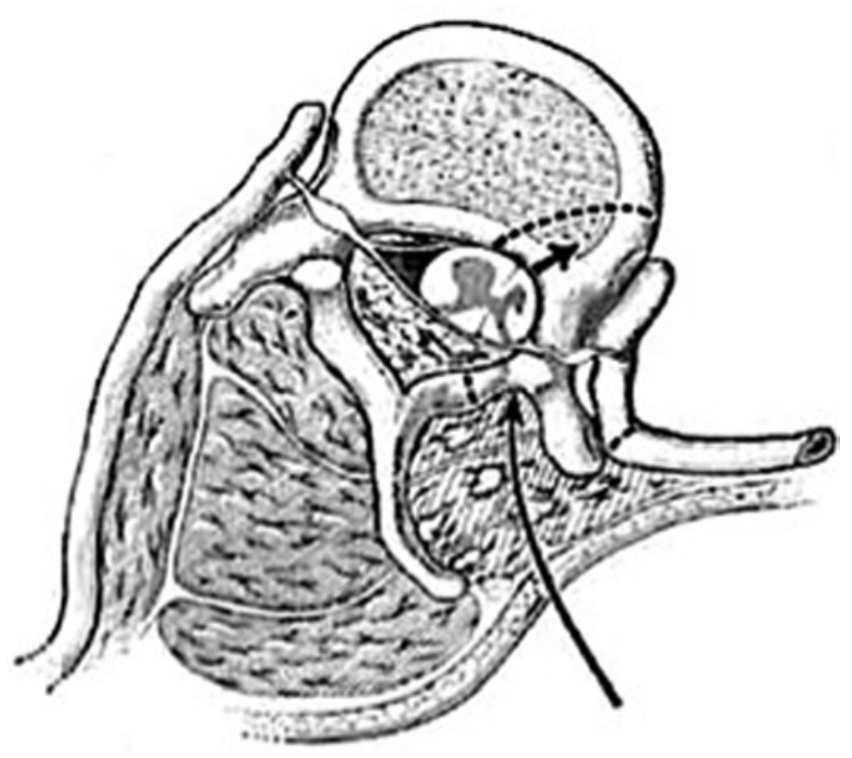

FIG. 8. Illustration of the approach (curved arrows) and bony resection (dotted lines) for decompression of the spinal cord in kyphoscoliosis. Reproduced from Guiot G, Anquez L, Comoy C: Presse Med 72:573578, 1964. Published with permission. and above the patient so that the surgeon could view it without disturbing his or her position. Radioscopic control was afforded through a foot pedal controlled by either the surgeon or his assistant. Before starting the case, an intrathecal lumbar catheter was placed for the administration of contrast and air, which were to be injected intermittently for live imaging of tumor removal. ${ }^{18,24}$ The introduction of live fluoroscopy for real-time delineation of tumor contour allowed surgeons for the first time to safely and comfortably venture beyond the sella. This accomplishment was well illustrated by Guiot's student from Montreal, Jules Hardy, in his paper on radiofluoroscopic control in transsphenoidal surgery. Hardy wrote, "A tumor with large midline suprasellar extension producing significant displacement of the third ventricle is amenable to transsphenoidal attack provided the procedure is combined with radiofluoroscopic monitoring." 27 In response to critics of the transsphenoidal route at the time, Hardy remarked in a tone of liberation, "Criticism of trans-sphenoidal surgery has centered on the fact of relatively inadequate exposure of the pituitary fossa. With the advent of modern radiological methods [fluoroscopy at the time of Guiot and Hardy] this disadvantage of the procedure has been overcome." 24

Apart from ensuring a safe trajectory toward the sphenoid sinus and allowing for careful resection of sellar lesions with suprasellar involvement, Guiot made possible the direct observation of tumor extirpation with the restoration of normal midline anatomy, allowing one to conceive guidelines for the route of resection based on anatomo-radiological correlation of pituitary fossa tumor growth patterns (Fig. 9). ${ }^{27}$ Third ventricular displacement and volume on fluoroscopy became an important indicator of the extent of tumor resection (Fig. 10). In addition, the complication of a CSF fistula was avoided using televised fluoroscopy to prevent compromising the arachnoid membranes. ${ }^{18,24}$ Guiot would go on to use televised fluoroscopy to correct and avoid symptomatic empty sella syndrome due to transsphenoidal resection of large pituitary adenomas, which was performed by packing the sella with bone plaques to elevate the diaphragma sellae and restore the normal position of the chiasm, preventing traction and optic compromise (Fig. 11). Guiot systematically applied the aforementioned principle with fluoroscopic guidance in over 200 pituitary adenoma cases with great success. ${ }^{34}$

\section{Journeying Along Guiot's Path: Advent of Microscopy and Endoscopy}

Guiot's introduction of live fluoroscopic image guidance to transsphenoidal surgery guaranteed the survival of this approach, reestablished its indispensable role in tackling sellar and suprasellar pathology, and set the stage for future innovators. Hardy learned Guiot's techniques, including fluoroscopy, and amplified them with the integration of the operating microscope, which provided superior magnification and illumination (Fig. 12). ${ }^{25}$ The microscope led to refinements in surgical dissection techniques that allowed for the discovery of microadenoma and demonstrated the possibility of a complete surgical cure in patients with hypersecretory lesions. ${ }^{26}$ With the advent of endoscopy and its introduction to transsphenoi- 


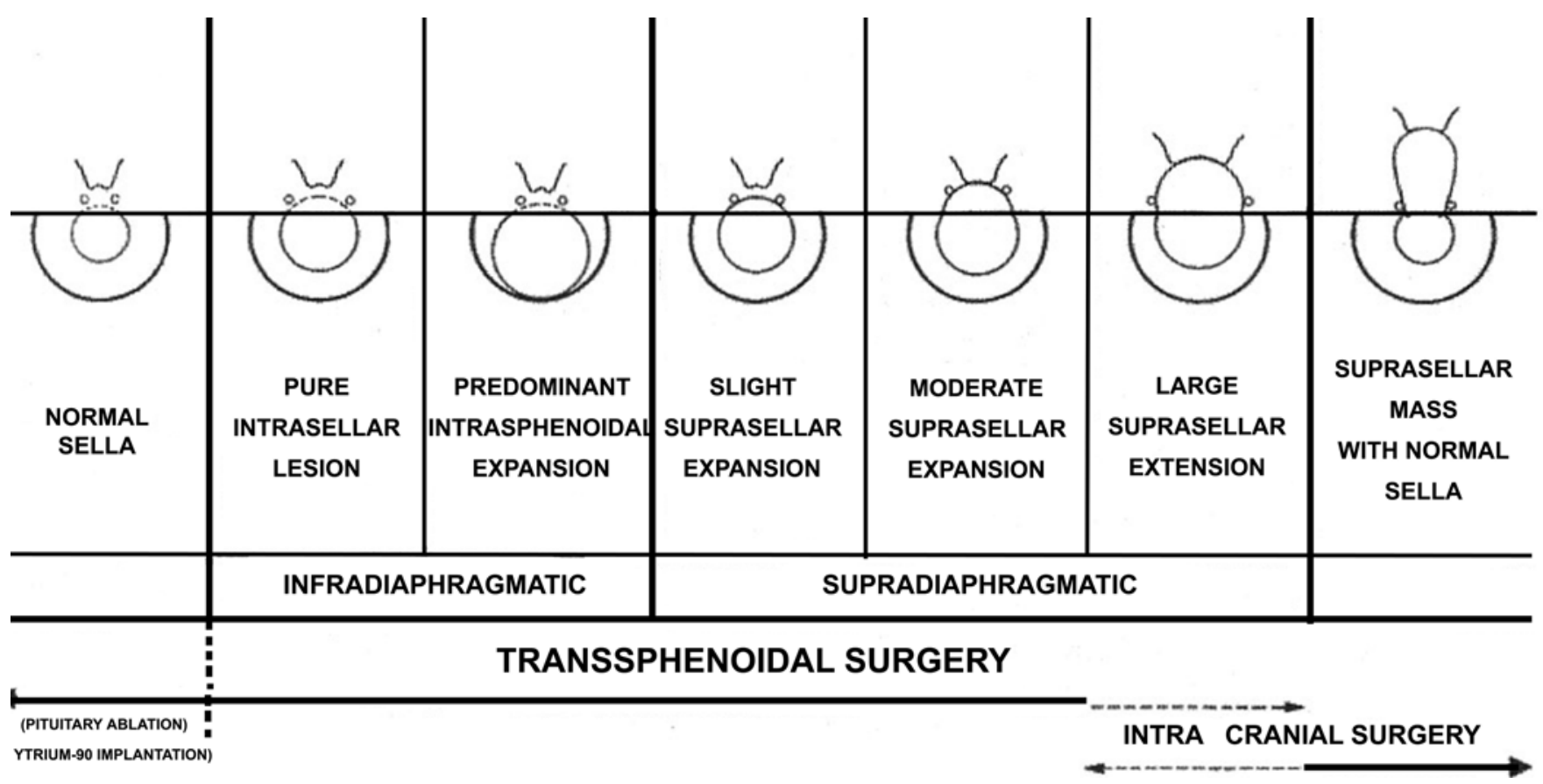

FIG. 9. Classification of anatomo-radiological correlation of pituitary fossa growth patterns and their suggested route of resection. Reproduced from Hardy J, Wigser SM: J Neurosurg 23:612-619, 1965.

dal surgery as an adjunctive means of extirpating sellar lesions, ${ }^{4,7}$ the anatomically blind corners of the suprasellar and parasellar regions could be adequately assessed for tumor involvement. Almost a decade later, in 1987, Weiss extrapolated the principles of skull base surgery to transsphenoidal surgery through his "extended" approach; this method has proven to be an effective and safe alternative to cranial approaches. ${ }^{1,3,42}$ Soon thereafter, Jho and Carrau, ${ }^{31}$ Jankowski et al., ${ }^{30}$ Sethi and Pillay, ${ }^{43}$ and Cappabianca et al. ${ }^{9}$ described the pure endoscopic approach.

\section{Conclusions}

Gerard Guiot was one of the most influential neurosurgeons of the first half of the 20th century. He not only advanced and safeguarded the role of transsphenoidal sur-

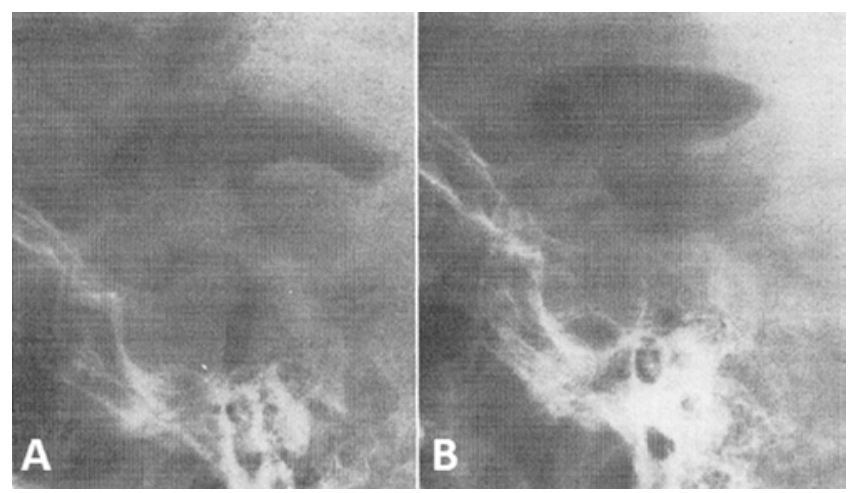

FIG. 10. A: Fluoroscopic pneumoencephalograph obtained during the time of Guiot and Hardy, demonstrating a large suprasellar expansion displacing the third ventricle. B: Return of near-normal third ventricular anatomical position and morphology after tumor resection. Reproduced from Hardy J, Wigser SM: J Neurosurg 23:612-619, 1965.

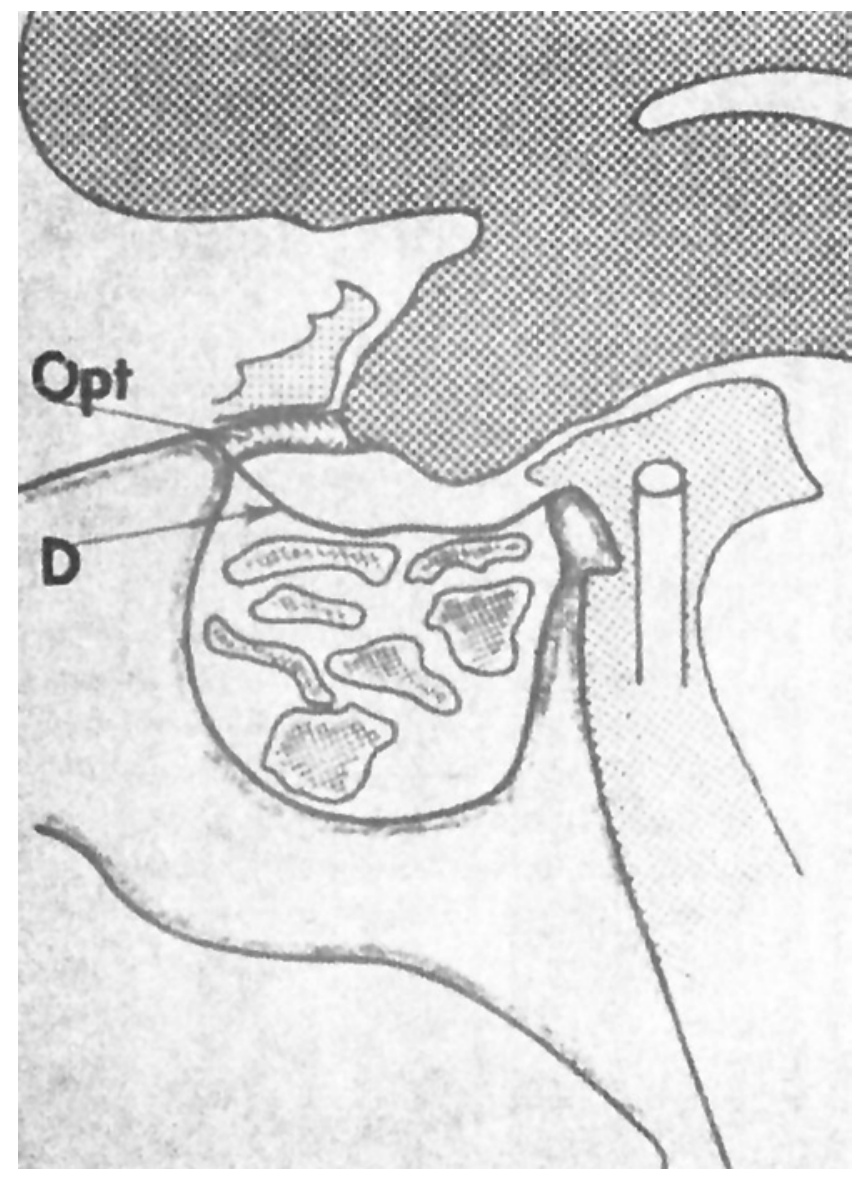

FIG. 11. Drawing depicting the intrasellar elevation of the diaphragma sellae (D) and optic apparatus (Opt) with bone planes. Reproduced with permission from Olson DR, Guiot G, Derome P: J Neurosurg 37:533537, 1972 


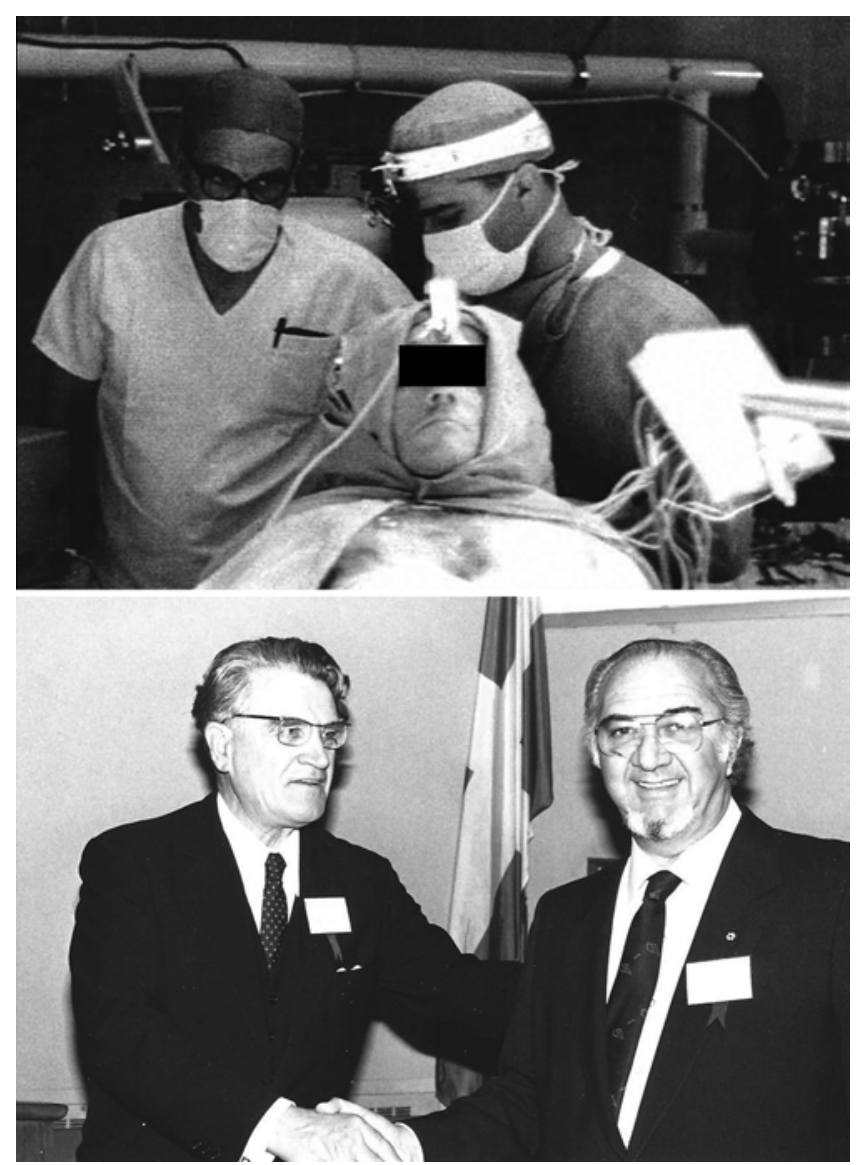

FIG. 12. Upper: Photograph showing Guiot (at left) supervising Jules Hardy, who performs a stereotactic procedure on a parkinsonian patient. Hardy traveled to France to study stereotactic surgery under Guiot, a pioneer in the field. During his time in France with Guiot, Hardy was introduced to transsphenoidal surgery to access lesions in and around the sella. Reprinted from Transsphenoidal Surgery, Ed 1, Laws ER, Lanzino $\mathrm{G}$, eds, History of transsphenoidal surgery for pituitary tumors, pp 4-9, Copyright 2010, with permission from Elsevier. Lower: Photograph from 1987 showing Guiot congratulating Hardy on the 25th anniversary of the introduction of transsphenoidal surgery in Montreal in 1962. Photograph from the personal collection of Jules Hardy.

gery and erased doubt about its safety and efficacy through his introduction of fluoroscopy, but he also made countless contributions to many different facets of neurosurgery that have changed the way we think and practice. Guiot's contributions effectively introduced an era of innovative progress that continues today.

\section{References}

1. Al-Mefty O, Kadri PA, Hasan DM, Isolan GR, Pravdenkova S: Anterior clivectomy: surgical technique and clinical applications. J Neurosurg 109:783-793, 2008

2. Albe-Fessard D, Arfel G, Guiot G, Derome P, Hertzog E, Vourc'h G, et al: Electrophysiological studies of some deep cerebral structures in man. J Neurol Sci 3:37-51, 1966

3. Altay T, Krisht KM, Couldwell WT: Sellar and parasellar metastatic tumors. Int J Surg Oncol 2012:647256, 2012

4. Apuzzo ML, Heifetz MD, Weiss MH, Kurze T: Neurosurgical endoscopy using the side-viewing telescope. Technical note. J Neurosurg 46:398-400, 1977
5. Arfel G, Walter S, Guiot G, Derome P, Langie S: Thalamic stereo-encephalography. Electroencephalogr Clin Neurophysiol 28:85, 1970

6. Biggart JH, Dott NM: Pituitary tumours. Their classification and treatment. Br Med J 2:1206-1208, 1936

7. Bushe KA, Halves E: [Modified technique in transsphenoidal operations of pituitary adenomas. Technical note (author's transl).] Acta Neurochir (Wien) 41:163-175, 1978 (Ger)

8. Cairns H: The ultimate results of operations for intracranial tumours: a study of a series of cases after a nine-year interval. Yale J Biol Med 8:421-492, 1936

9. Cappabianca P, Alfieri A, Colao A, Cavallo LM, Fusco M, Peca C, et al: Endoscopic endonasal transsphenoidal surgery in recurrent and residual pituitary adenomas: technical note. Minim Invasive Neurosurg 43:38-43, 2000

10. Decq P, Schroeder HW, Fritsch M, Cappabianca P: A history of ventricular neuroendoscopy. World Neurosurg 79 (2 Suppl):S14.e1-S14.e6, 2013

11. Dell B, Talairach MJ, Lairy-Bounes GC, Dell P: [Electrophysiological examinations of the thalamus in man.] Rev Neurol (Paris) 87:191-195, 1952 (Fr)

12. Dott NM, Bailey P, Cushing H: A consideration of the hypophyseal adenomata. Br J Surg 13:314-366, 1925

13. Gandhi CD, Christiano LD, Eloy JA, Prestigiacomo CJ, Post KD: The historical evolution of transsphenoidal surgery: facilitation by technological advances. Neurosurg Focus 27(3):E8, 2009

14. Gillingham FJ, Watson WS, Donaldson AA, Naughton JA: The surgical treatment of parkinsonism. Br Med J 2:13951402,1960

15. Grosvenor AE, Laws ER: The evolution of extracranial approaches to the pituitary and anterior skull base. Pituitary 11:337-345, 2008

16. Guiot G: Ventriculo-cisternostomy for stenosis of the aqueduct of Sylvius. Puncture of the floor of the third ventricle with a leucotome under television control. Acta Neurochir (Wien) 28:275-289, 1973

17. Guiot G, Anquez L, Comoy C: [Surgical treatment of paraplegia caused by kypho-scoliosis. Surgical technic.] Presse Med 72:573-578, $1964(\mathrm{Fr})$

18. Guiot G, Derome P, Demailly P, Hertzog E: [Unexpected complication of complete exeresis of voluminous pituitary adenomas.] Rev Neurol (Paris) 118:164-167, 1968 (Fr)

19. Guiot G, Hertzog E, Rondot P, Molina P: Arrest or acceleration of speech evoked by thalamic stimulation in the course of stereotaxic procedures for Parkinsonism. Brain 84:363379,1961

20. Guiot G, Piwnica A: [Carotido-cavernous aneurysm operated on under deep hypothermia with circulatory arrest.] Mem Acad Chir (Paris) 92:224-228, 1966 (Fr)

21. Guiot G, Rougerie J, Arfel G, Dubost C, Blondeau P: ["Extreme cold" in neurosurgery. Possibilities and future perspectives. Reflections apropos of the 1st case of vascular malformation operated on with success under prolonged circulatory arrest and hypothermia at 10 degrees]. Neurochirurgie 6:332-346, $1960(\mathrm{Fr})$

22. Guiot $G$, Thibaut B: L'exérèse des adénomes de l'hypophyse par voie trans-sphénoïdale, in Guiot G (ed): Adénomes Hypophysaires. Paris: Masson, 1958, pp 165-180

23. Hardy J: Neurosurgeon of the year. Gerard Guiot. Surg Neurol 11:1-2, 1979

24. Hardy J: [Surgery of the pituitary gland, using the open trans-sphenoidal approach. Comparative study of 2 technical methods.] Ann Chir 21:1011-1022, 1967 (Fr)

25. Hardy J: Transsphenoidal microsurgery of the normal and pathological pituitary. Clin Neurosurg 16:185-217, 1969

26. Hardy J: Transsphenoidal microsurgery removal of pituitary micro-adenoma. Prog Neurol Surg 6:200-216, 1975

27. Hardy J, Wigser SM: Trans-sphenoidal surgery of pituitary 
fossa tumors with televised radiofluoroscopic control. J Neurosurg 23:612-619, 1965

28. Hassler R, Schmidt K, Riechert T, Mundinger F: Stereotactic treatment of action myoclonus in a case of combined status marmoratus and multiple sclerosis. A contribution to the pathophysiology of basal ganglia with multiple lesions in both the striatum and the substantia nigra. Confin Neurol 37:329-356, 1975

29. Horsley V, Clarke R: The structure and function of the cerebellum examined by a new method. Brain 31:45-124, 1908

30. Jankowski R, Auque J, Simon C, Marchal JC, Hepner H, Wayoff M: Endoscopic pituitary tumor surgery. Laryngoscope 102:198-202, 1992

31. Jho HD, Carrau RL: Endoscopy assisted transsphenoidal surgery for pituitary adenoma. Technical note. Acta Neurochir (Wien) 138:1416-1425, 1996

32. Kelly PJ, Derome P, Guiot G: Thalamic spatial variability and the surgical results of lesions placed with neurophysiologic control. Surg Neurol 9:307-315, 1978

33. Laitinen LV: Personal memories of the history of stereotactic neurosurgery. Neurosurgery 55:1420-1429, 2004

34. Lanzino G, Laws ER Jr, Feiz-Erfan I, White W: Transsphenoidal approach to lesions of the sella turcica: Historical overview. Barrow Q 18:4-8, 2002

35. Leksell L: A stereotaxic apparatus for intracerebral surgery. Acta Chir Scand 99:229-233, 1950

36. Lenz FA, Tasker RR, Kwan HC, Schnider S, Kwong R, Murayama $Y$, et al: Single unit analysis of the human ventral thalamic nuclear group: correlation of thalamic "tremor cells" with the 3-6 Hz component of parkinsonian tremor. J Neurosci 8:754-764, 1988

37. Lhermitte J, de Ajuriaguerra J, Hecaen $\mathrm{H}$ : [Clinical study of the thalamic syndrome.] Rev Neurol (Paris) 83:20-22, 1950 (Fr)

38. Liu JK, Das K, Weiss MH, Laws ER Jr, Couldwell WT: The history and evolution of transsphenoidal surgery. J Neurosurg 95:1083-1096, 2001

39. Olson DR, Guiot G, Derome P: The symptomatic empty sella. Prevention and correction via the transsphenoidal approach. J Neurosurg 37:533-537, 1972

40. Rahman M, Murad GJ, Mocco J: Early history of the stereotactic apparatus in neurosurgery. Neurosurg Focus 27(3):E12, 2009

41. Rockoff SD, Ommaya AK, Cohen G: A fluoroscopically controlled adjustable midline localizer for stereotaxic surgery. A modification of the Guiot-Gillingham technique. Am J Roentgenol Radium Ther Nucl Med 91:1138-1143, 1964
42. Rosegay H: Cushing's legacy to transsphenoidal surgery. J Neurosurg 54:448-454, 1981

43. Sethi DS, Pillay PK: Endoscopic management of lesions of the sella turcica. J Laryngol Otol 109:956-962, 1995

44. Simpson DA, David DJ: Herbert Moran Memorial Lecture. World War I: the genesis of craniomaxillofacial surgery? ANZ J Surg 74:71-77, 2004

45. Spiegel EA, Wycis HT, Marks M, Lee AJ: Stereotaxic apparatus for operations on the human brain. Science 106:349350,1947

46. Talairach J, Hecaen H, David M, Mounier M: Recherches sur la coagulation thérapeutique des structures sous-corticales chez l'homme. Rev Neurol (Paris) 81:4-24, 1949

47. Tessier P, Guiot G, Derome P: Orbital hypertelorism. II. Definite treatment of orbital hypertelorism (OR.H.) by craniofacial or by extracranial osteotomies. Scand J Plast Reconstr Surg 7:39-58, 1973

48. Uchimura Y, Narabayashi H: [Stereoencephalotomy.] Psychiat Neurol Jpn 52:265-270, 1951 (Jpn)

49. Walter S, Basso A, Guiot G, Barrionuevo G, Gautron M: Afterdischarges elicited by electrical thalamic stimulation in the hemicerebellectomized baboon. Adv Neurol 10:133-145, 1975

50. Woodhall B, Sealy WC, Hall KD, Floyd WL: Craniotomy under conditions of quinidine-protected cardioplegia and profound hypothermia. Ann Surg 152:37-44, 1960

51. Zada G, Liu C, Apuzzo ML: "Through the looking glass": optical physics, issues, and the evolution of neuroendoscopy. World Neurosurg 79 (2 Suppl):S3-S13, 2013

\section{Author Contributions}

Conception and design: Krisht, Sorour. Acquisition of data: Krisht, Sorour, Cote, Hardy. Analysis and interpretation of data: Krisht, Sorour, Cote. Drafting the article: Krisht, Sorour, Cote. Critically revising the article: all authors. Reviewed submitted version of manuscript: all authors. Approved the final version of the manuscript on behalf of all authors: Couldwell. Study supervision: Couldwell.

\section{Correspondence}

William T. Couldwell, Department of Neurosurgery, University of Utah, 175 N. Medical Dr. E., Salt Lake City, UT 84132. email: william.couldwell@hsc.utah.edu. 